\title{
Environmental Concerns in the Design and Management of Pallets
}

\author{
Jyotirmoyee Bhattacharjya $^{1}$ and Peter Kleine-Moellhoff ${ }^{2}$ \\ ${ }^{1}$ Institute of Transport and Logistics Studies, \\ The University of Sydney, Sydney, NSW, 2006, Australia \\ ${ }^{2}$ ESB Business School, Reutlingen University, \\ Alteburgstr. 150, D-72762, Reutlingen, Germany \\ jyotirmoyee. bhat tacharjya@sydney . edu.au, \\ peter.kleine-moellhoff@reutlingen-university.de
}

\begin{abstract}
Planning for sustainable reindustrialization necessitates considerations for environmentally sustainable production processes, packaging and logistics. Pallets are essential for the movement of goods around the world. Millions of pallets enter the global supply chain every year and are used, reused and either discarded or recycled. Since billions of pallets of different types are in use at any time, minimization of overall environmental impacts can be achieved only through process improvements and careful consideration of pallet types for various activities. The paper reviews the current management practices with respect to pallets and identifies issues in different points of the life cycle.
\end{abstract}

Keywords: Pallet life cycle, pallet management, environmental sustainability, stakeholder theory.

\section{Introduction}

A recent observation by John Mead, the previous Chair of the International Organization for Standardization (ISO) Technical Committee (TC) 51, Pallets for unit load method of material handling, provides an useful context for the discussion in this paper: "Although pallets are largely taken for granted, these humble, flat, structures can be said to form one of the basic blocks of global supply chains. Billions are currently in existence, a mark of confidence based on 50 years of worldwide experience" ([1], p. 18). His comments highlight two important issues that have an impact on resource scarcity and sustainable landfill usage considerations: pallets are an indispensible component of global trade and millions of pallets enter the global supply chain every year. As various arguments over the environmental impacts of different types of pallets and management practices continue to rage within the pallet industry, there appears to be a growing volume of information in support of all sides of these arguments. Practitioner driven pallet life cycle assessments have served to add more confusion to these arguments. However, there is limited independent academic research that could provide some informed guidance for business decision makers. While there has been a recent attempt at modeling the cost and environmental 
trade-off for companies when selecting pallets [2], the model does not address the complexity of relationships between various stakeholders and the diversity of conditions influencing pallet choice and usage practices. In practice such choices may be driven by the regulatory environment and the dominant exchange/ pooling services in the region, and there may be a range of issues associated with subsequent management practices. This paper outlines key practices around the globe in relation to different stages of the pallet life cycle and discusses their environmental implications while highlighting the roles played by different stakeholders.

\section{The Pallet Life Cycle and Environmental Concerns}

\subsection{Pallet Design and Manufacturing}

Pallet design and associated innovation needs to be guided by the needs of key players along the supply chain. In essence, a shipper's choice of pallet is informed by the weight of the product, the environment through which a product will travel and the types of vehicles that will be involved in moving the pallet load [3]. A pallet buyer must also consider the standard pallet sizes used in a particular industry and in different international destinations [4]. To facilitate shipping between major trading regions, ISO/TC 51 has defined six sizes of pallets in the standard ISO 6780:2003, Flat pallets for intercontinental materials handling - Principal dimensions and tolerance [1]. Thus evolution in pallet manufacturing has involved the adoption of a variety of materials and designs.

Pallet buyers are faced with an increasing number of options whose environmental impacts need careful consideration. Wood (see Fig. 1) remains the material of choice for pallet design (estimated to be used in over $90 \%$ of applications around the globe) but plastic pallets have been gaining in popularity because of their durability and light weight [1]. A debate continues to rage over whether wood (which requires the felling of trees) or plastic (created from a non-renewable resource) is the more eco-friendly raw material [5]. However, wooden pallets are seen to have an advantage over plastic in terms of the carbon dioxide emissions during the manufacturing process. There are other considerations in the wood versus plastic debate. The requirements outlined in the International Standard for Phytosanitary Measures 15 (ISPM 15) imply additional costs for shippers with the inclusion of processes such as heat treatment or fumigation of wooden pallets [6]. This makes plastic pallets an attractive option for shipping time-sensitive products which could be affected by delays in the certification of wooden pallets. As more buyers consider plastic pallets, there is likely to be an increased focus on the flame retardant capabilities of these pallets and the adequacy of sprinkler systems in existing warehouses [3]. However, chemicals added to give plastic pallets their flame retardant quality may turn out to be toxic in nature. The plastic pallet company, Intelligent Global Pooling Systems (iGPS), for instance, recently reached a voluntary agreement with the US Environmental Protection Agency (EPA) to end the use of the chemical decabromodiphenyl ether (DecaBDE) as a flame retardant in its pallets over a period of three to four years [7]. The EPA was concerned by the persistent and toxic nature of the chemical and the possibility of it leaching into food carried by iGPS pallets. 


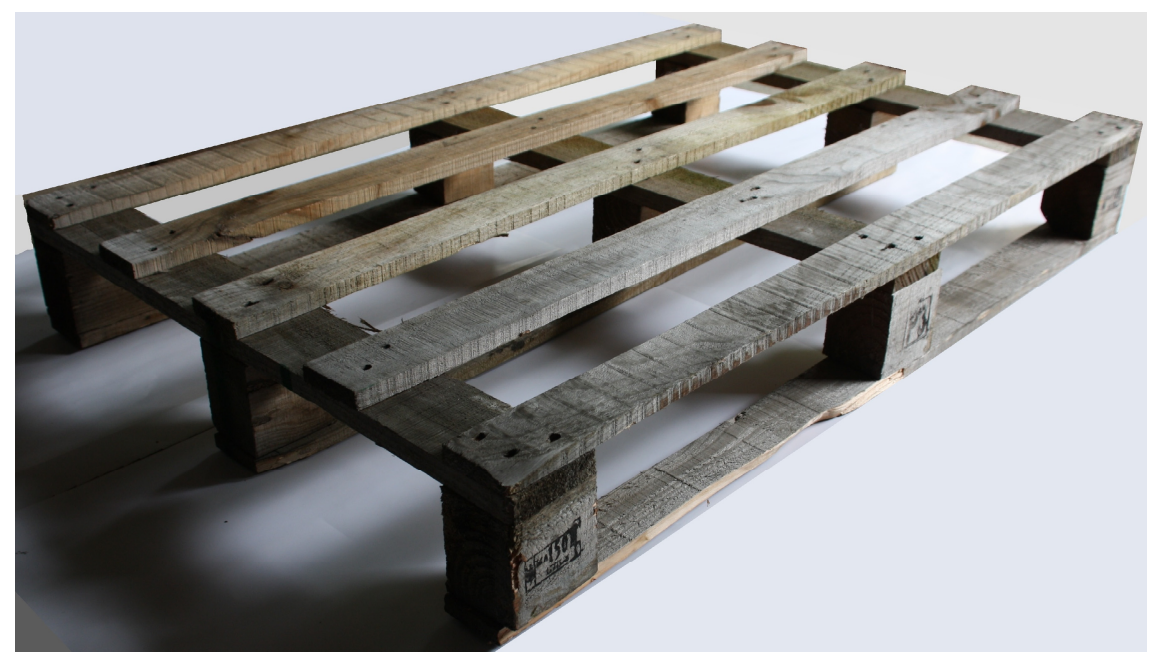

Fig. 1. A single-use wooden pallet (European size: $1200 \mathrm{~mm} \mathrm{X} 800 \mathrm{~mm} \mathrm{X} 150 \mathrm{~mm}$ ). (Source: Second Author).

The cost and shortage of wood in Asian countries have also led to an examination of other options [1]. Corrugated paper pallets for lighter loads and pallets made from reconstituted wood are other options. Lightweight aluminium pallets have also become a reliable option. The arguments in favor of steel pallets that are coated to prevent rusting are similar to those for aluminum pallets: light weight, durability and recyclability at the end of a multiyear life [4].

\subsection{The Working Life of a Pallet - Pallet Use, Reuse and Repair}

Pallets may be custom sized according to user requirements and designed for singleload use [1]. However, the reuse of general purpose pallets is a more cost-effective and environmentally sustainable solution. While both wooden and plastic pallets can be repaired several times during their working life, the former are easier to repair [5]. The ISO standard (ISO 18613:2003) specifies the maximum defects allowed before a flat wooden pallet needs to be repaired; however, the responsibility for carrying out appropriate inspection processes and ensuring the safety of reused pallets lies with companies that maintain pallet pools [1]. A range of practices have been developed across the globe in relation to pallet reuse.

Pallet use and reuse may occur between members of a designated industry group in a particular country or region. In the US, the Grocery Manufacturers Association (GMA) exchange pallets that constantly circulate between various owners with the ownership of a pallet being transferred with the product load [8]. In Canada, the Canadian Pallet Council (CPC) provides a pallet exchange system (a pool of about seven million distinctive orange hardwood pallets) for its 1200 pallet-user members. While initially created in 1977 on the basis of pallet ownership, the CPC now provides pallet rental, repair and retrieval services through its pallet industry members. Its services also include the provision of online asset management tools. In 
Europe, the European Pallet Association (EPAL) was formed in 1991to maintain a Europe-wide exchange wooden pallet pool for the European Railways. Its membership includes users, producers, dealers, repairers and transporters. It undertakes regular inspection of pallets produced by EPAL licensed manufacturers.

Pallet reuse may sometimes be facilitated through partnerships between individual companies with different core capabilities The UK based building materials provider, CEMEX addressed the need for reuse by forming an alliance with packaging specialists European Logistics Management to ensure the collection, repair and return of pallets. Without such an arrangement these pallets would either have to be thrown or shredded. From the perspective of both CEMEX and its customers there were financial benefits from the implementation of such a system. The cost of wooden pallets had risen by $15 \%$ in 2007 and 20\% in 2008 and the landfill tippage charges were increasing as well [9]. By the end of the first year the company claimed to have recovered $20 \%$ of the 250,000 pallets sent out to customers.

With the growth of pallet pooling services, it has become less of a necessity for suppliers/ manufacturers to buy and own their own pools. Pallet pooling service providers such as CHEP, iGPS and Loscam provide similar services which involve issuing pallets to manufacturers or growers, collection of empty pallets from downstream supply chain partners and performing inspections and repairs of the returned pallets. The pooling process has its share of problems as highlighted by this recent court case in Australia between the hardware chain Bunnings Warehouse and CHEP Australia : "In May 2010, Justice McDougall in the Supreme Court of New South Wales ordered Bunnings to pay $\$ 11$ million in damages to Chep for conversion and detinue of 64,690 pallets it had unlawfully detained over a five year period......This is despite the fact that during that entire time, a customer of Chep (whomever that may be) was paying hire charges for precisely the same pallets" [10]. Inadequate auditing of pallets remains a common occurrence within the pallet hire industry in Australia. As illustrated by the judgement in favour of CHEP, such incidents can prove to be quite costly for pallet hirers and companies that exchange pallets with them in the course of their normal business processes. John Stuart, owner of the Melbourne based consultancy firm Pallet Loss Prevention Pty Ltd, aptly summarizes the problem: "If someone doesn't transfer their pallets off their account into your account, they will lose them... Pallet controllers on the receiving end can see that they haven't put their transfers through. Standard practice at the moment is not to tell them because everybody is losing pallets, so they can't afford to tell anybody else... Pallets are like a black art. People don't understand how easy it is to lose pallets. When you lose pallets, if you don't realize, they keep on paying and paying the hire charges, in the hope they will get them back, and they don't" ([11], p. 89). Although hire agreements are in place between pallet hire companies and hirers in Australia, the application of these agreements in the practices of companies that use hired pallets when conducting business with each other is fairly limited. The Pallet Hire Industry Code of Conduct (2010) has recently been developed for the local industry in Australia but this is voluntary. The use of appropriate software packages, much greater emphasis on the development of adequate internal policies and procedures for pallet control, better relationships between pallet controllers in adjacent companies in the supply chain and appropriate training for truck drivers transporting the pallets have all been suggested as potential solutions for addressing 
this problem [11]. In essence, for pallet pooling to continue to be an environmentally sustainable solution it needs to remain a cost effective option for different players in the supply chain. However, the right combination of people, process and technology in this context still appears to be eluding many companies.

\subsection{The Working Life of a Pallet - Transportation}

The more durable the pallet, the more trips it can make during its lifetime. While manufacturers of plastic pallets claim these are more durable than wooden ones [12] and others highlight the durability of aluminium and steel pallets (e.g., [4]), there is a lack of independent estimates regarding the number of trips that can be handled by pallets built from different materials. The fact that these pallets may be used for very different purposes also makes the comparison a complex issue. Two key sides of the debate iGPS (leading plastic pallets pooling service) and CHEP (leading wooden pallet pooling service) continue to disagree over the number of trips that their respective pallets can handle [5]. A significant issue in relation to pallet transportation is the weight of the pallet. It is argued that the transportation of plastic pallets requires the consumption of less diesel fuel since these pallets generally weigh only about half as much as wood ones. Apart from transportation needs associated with the working life of a pallet, the repair and reuse of pallets, discussed in the previous section, also implies the need for transportation of damaged pallets to repair locations and hence additional fuel consumption. CHEP claims to have minimized greenhouse gas emissions from repair related pallet transportation in the US by building service centres close to where their customers use these pallets [5]. However, there is inadequate research regarding the practices of pallet related service providers around the globe.

\subsection{Pallet End-of-Life}

There are issues to consider in managing end-of-life related issues as well. The disposal of plastic pallets is also problematic as plastic is not biodegradable and emits methane gas when it starts to decompose [5]. While wood does not have the same problem, landfill disposal of wooden pallets has become an unwelcome practice across many states and municipalities in the US (e.g., Buehlmann, et al., 2009). Recycling is increasingly seen as the acceptable option. Wooden, plastic, aluminium and steel pallets can all be recycled ([4]; [5]). A damaged wooden pallet can be used ground up and used to produce mulch or animal bedding. A plastic one can also be melted to produce a new plastic pallet, but there is an energy cost associated with this process. Recyclability brings other problems with it as well. Between November 2010 and May 2011 the Los Angeles County Sheriff's department has been reported to have recovered US\$1.3 million in stolen pallets and reusable packaging [13]. Such thefts have been attributed to factors such as the lack of adequate security in larger stores and inadequate secure storage space in smaller ones and have been estimated to have cost businesses in the San Gabriel Valley around US\$10 million per year. These incidents have led to lawsuits against some recyclers and highlighted the need for law enforcement authorities to work with recyclers to prevent the purchase of stolen plastics. This also suggests that the point at which a pallet is recycled may depend on 
issues other than ISO standards and inspection processes of pallet owners. While theft results in an obvious cost for businesses from which they are stolen, the repeated recycling of pallets has significant energy costs associated with it as well. These issues suggest the need for further research into the implementation of end-of-life solutions for different types of pallet in the context of business practices in different industry sectors, law enforcement and regulatory environments.

\subsection{Pallet Life Cycle Assessments}

Both CHEP and iGPS provide online calculators in a bid to assure customers of their green credentials. Both have commissioned studies by independent consultancy firms to make their respective cases. The report developed by Franklin Associates for CHEP concluded that CHEP's pallet pooling systems "produce much less production waste and recycling/disposal waste than exchange and one-way systems because of the high material efficiencies and controlled end-of-life management for CHEP pallets" ([8], p. ES-5). Another life cycle assessment by consultancy firm Environmental Resources Management for iGPS concluded that, "iGPS plastic pallet had lower environmental impacts in all impact categories compared to the typical pooled wooden pallet, and a substantially smaller environmental footprint than the single-use pallet" ([14], p. ii). A subsequent study by CHEP in 2009 suggested that wooden pallets perform better than their plastic counterparts in relation to the generation of solid waste, energy consumption and greenhouse gas emission [16]. Clearly, independent studies which take into account a broader range of pallet types as well as industry and country/region specific pallet management practices could help to provide some clarity and better inform the decisions made by pallet hirers/owners.

\section{A Stakeholder Theory Perspective}

A useful theoretical perspective in this context is stakeholder theory which is built on the premise that effective firms need to manage all relationships that affect or are affected by the achievement of the objectives of the organization [17]. Broadening Freeman's [17] original conceptualization, Clarkson [18] defines the concept of primary stakeholders as: "Primary stakeholder groups typically are comprised of shareholders and investors, employees, customers, and suppliers, together with what is defined as the public stakeholder group: the government and communities that provide infrastructure and markets, whose laws and regulations must be obeyed, and to whom taxes and other obligations may be due" (p. 106). Stakeholder groups have been classified in a number of different ways in relation to issues such as power, dependence, reciprocity, legitimacy and actual and potential relationships. Synthesizing the relevant literature, Mitchell et al. [19] provide a comprehensive classification which identifies the following types of firm-stakeholder relationships: a firm and a stakeholder are in a non-trivial relationship (potentially of a transactional nature); stakeholder is dominant; firm is dominant; stakeholder and firm are mutually dependent; stakeholder and firm are in a contractual relationship (the contract is the basis for legitimacy); and stakeholder has an interest in the firm (legitimacy is not 
implied). While the development of stakeholder theory has taken a number of directions, the basic ideas of the influence of stakeholders on the firm and vice versa and the classification of different stakeholder groups could provide useful lenses for examining activities of different organizations involved in the life cycle of a pallet. Wal-Mart, for example, requires its globally distributed suppliers to complete a sustainability assessment [20]. However, the impact on the pallet management practices of upstream supply chain partners based on the environmental sustainability requirements of downstream players requires further research. Practices of government agencies around the globe are likely to vary from those of the EPA as well.

Pallet life cycle assessment appears to be an area where further work is required beyond the claims and counterclaims of dominant pooling services. Stakeholder influences on life cycle assessments has recently been discussed in the research literature in the context of oil and gas and agricultural biotechnology [21]. Similar considerations for greater stakeholder engagement could potentially enrich the analysis of pallet life cycles. Furthermore, broadening the concept of life cycle assessment to economic-ecological efficiency analysis and incorporating both environmental impact and costs/value added could provide greater value for pallet hirers.

\section{Discussions}

This paper highlights key practices and sustainability issues in the management of the pallet life cycle around the globe. While the diversity in pallet life cycle management practices poses many challenges, it presents a great opportunity for researchers to identify solutions that are sustainable in the long term. The authors are currently involved in modeling environmental impacts for different pallet types based on current pallet life cycle management practices and a number of data sources. The outcomes of the modeling exercise will be presented at the conference.

\section{References}

1. Mead, J.M.B.: Reliable pallets - Carrying world trade on their backs, ISO Focus+, pp. 18-19 (February 2010)

2. Bilbao, A.M., Carrano, A.L., Hewitt, M., Thorn, B.K.: On the environmental impacts of pallet management operations. Management Research Review 34, 1222-1236 (2011)

3. Witt, C.E.: Flame-retardant pallets (2003), http://mhlnews.com/transportpackaging/mhm_imp_3584/

4. Forcinio, H.: Packaging Forum: Particulate-Free Pallets, Pharmaceutical Technology, 32-38 (September 2004)

5. Lacefield, S.K.: How green are your pallets? DC Velocity 67-72 (November 2008)

6. Grande, J.A.: Plastic Pallets Gain Ground in an Eco-Conscious World. Plastics Technology, 58-75 (September 2008)

7. Harrington, R.: Plastic pallet company defiant in face of DecaBDE phase-out pact (2009), http: / / www . foodproductiondaily.com/Quality-Safety/Plasticpallet-company-defiant-in-face-of-DecaBDE-phase-out-pact 
8. Franklin Associates: Life cycle inventory of wood pallet systems - Final summary report (2007), http: / / www . brambles. com/BXB / Company / ShowPage. aspx?CPID=3467

9. CEMEX: $20 \%$ of pallets returned in first year of CEMEX's pallet retrieval scheme (2009), http: / /www.cemex.co.uk/ac/ac_pr_20091001.asp

10. Harwood Andrews Lawyers: Pallet Hire Mystery Victoria Transport Association Inc. Priority Report No. 45 (June/July 2010),

http: / / www . vta.com.au/Default.aspx?tabid\%20=1074

11. Gregory, G.: Preventive Measures: Avoid Pallet Loss. Australias Best Manufacturing 2, 86-89 (2011)

12. Schiavo, B.: A pallet for every taste, Frozen Food Age, 44-47 (June 2008)

13. LeBlanc, R.: \$1.3 million in stolen reusable packaging and pallets recovered in Los Angeles -\$ A 10 million annual problem (2011), http://packagingrevolution. net/1-3million-in-stolen-reusable-packaging-and-pallets-recoveredin-los-angeles-a-10-million-annual-problem/

14. Environmental Resources Management: Streamlined life cycle assessment of iGPS

15. Typical pooled wooden pallets, and single use wooden pallets (2008), http://www.igps.net/pdf/Pallet_LCA_Brief_7_30_2008.pdf

16. Brindley, C.: Life Cycle Analysis Underscores Environmental Challenges of Plastic Pallets (2010), http://www.palletenterprise.com/articledatabase/view. asp?articleID $=3073$

17. Freeman, R.E.: Strategic Management: A stakeholder approach. Pitman, Boston (1984)

18. Clarkson, M.B.E.: A stakeholder framework for analysing and evaluating corporate social performance. The Academy of Management Review 20, 92-117 (1995)

19. Mitchell, R.K., Agle, B.R., Wood, D.J.: Toward a theory of stakeholder identification and salience: Defining the principle of who and what really counts. The Academy of Management Review 22, 853-886 (1997)

20. Bair, P.: Why Walmart's better supplier scorecard is a big deal (2012), http: / /www.greenbiz . com/blog/2012/04/19/why-walmarts-bettersupplier-scorecard-big-deal

21. Matos, S., Hall, J.: Integrating sustainable development in the supply chain: The case of life cycle assessment in oil and gas and agricultural biotechnology. Journal of Operations Management 25, 1083-1102 (2007) 